\title{
ADAPTATION OF CREW RESOURCE MANAGEMENT TRAINING IN HIGH-RISK INDUSTRIES
}

\author{
V. SCHUERMANN \& N. MARQUARDT \\ Rhine-Waal University of Applied Science, Kamp-Lintfort, Germany
}

\begin{abstract}
Crew resource management (CRM) is a training concept for optimising the use of all available resources (e.g. human, technology, organisation) within high-risk operations. It has its origins in aviation, but the principles and methods of CRM are already used in many other industries, like medicine or fire service. In order to raise the reliability of teams working in these industries, it is important to train them in non-technical skills (e.g. cooperation, managerial and leadership skills, decision making or situation awareness). Despite many years of research on CRM training, the amount of detailed information about these training programmes is often limited. Thus, the picture about CRM is not as clear as it should be. This makes it difficult to assess the effectiveness of such training programmes to prevent human error and industrial accidents. During a research project on the adaptation of CRM training, scientists of Rhine-Waal University in Kamp-Lintfort (Germany) conducted an empirical study. They interviewed 10 CRM experts from civil and military aviation, aircraft engineering, fire service, seafaring and medicine, about their experiences with CRM training to gain an overview about the current state of CRM in different industries. They identified cross-industry and industry-specific lessons learned as well as success factors of these training programmes. The results can be used to improve current CRM programmes, which in turn may increase safety standards in high-risk work domains.
\end{abstract}

Keywords: crew resource management, high risk operations, human error, team training.

\section{INTRODUCTION AND THEORY}

Human error is omnipresent and often causes major accidents [1]. The aviation industry, in particular, has identified failures of interpersonal communications, leadership or decision making as aspects of human error, which have resulted in the plurality of aircraft accidents [2]. To increase safety in high-risk industries, it is important to improve the interaction of teams working there. Therefore, some industries use crew resource management (CRM) to reduce human error. The Safety Regulation Group defines CRM 'as a management system which makes optimal use of all available resources - equipment, procedures and people - to promote safety and enhance the efficiency of flight operations' [3]. It is a training programme that focuses on non-technical skills like leadership or situation awareness [4]. CRM is most widely used in the aviation industry, but it has been adopted by other industries over the past few years.

\subsection{Development of CRM}

The origin of CRM training goes back to around 30 years ago when the National Aeronautics and Space Administration (NASA) sponsored a workshop to reduce pilot error on the flight 
deck. At this workshop, it was identified that human error is the leading cause for aircraft accidents. Since then, the implementation of CRM training began to spread globally [2].

Initially, these programmes were solely conceptualised for the cockpit crew. Several years later, training extended to flight attendants and maintenance staff [2]. Today, CRM is an obligatory and recurrent program for pilots, flight attendants and certifying maintenance staff. Depending on the responsible aviation authority, the content of the training is either dictated or just proposed [5,6].

After the dissemination of CRM in the aviation industry, some other industries endorsed the effects of training on safety. The medical industry recognized that most interpersonal problems that led to accidents were similar to those of the aviation industry [7], and therefore began to establish CRM. Moreover, human factors training was transferred to fire service, seafaring, oil and gas industries, nuclear power industry and the automotive industry [8-12]. Contrary to aviation, CRM in other industries is not mandatory.

\subsection{Training contents and methods}

A CRM training covers aspects like knowledge, skills, attitudes, cognitive processes and interpersonal relationships [13]. The usual core components of a training are non-technical skills, which deal with psychological conditions rather than technical knowledge. They can be divided into cognitive and social skills. Cognitive skills include situation awareness and decision making, whereas social skills include cooperation as well as leadership and managerial skills [4].

There are many possible ways to disseminate the training contents to the participants. Some examples of training methods are lectures, discussions, practical exercises, role play, simulations or case studies [14].

\section{RESEARCH OBJECTIVES}

Despite many years of research on CRM training and some evidence of its effectiveness, the amount of detailed information (e.g. training content, training environment) about such training is often limited [15]. CRM seems to lack standardisation. The absence of agreement regarding what it should include and how it should be designed has led to shortcomings [16]. Thus, it is difficult to assess the quality and suitability of the training programmes [15]. Moreover, previous research mainly focused on the aviation industry. Therefore, other sectors like fire service or seafaring are not sufficiently taken into account [e.g. 15,17]. Previous team training research, so far, investigated training content, team size and team membership stability as potential moderators of the relationship between training and team outcomes [18]. Based on this research and the defined objectives of the study, the following questions regarding CRM are raised:

- Is there an analysis of needs before training?

- Which training contents are used within training? How are they mediated?

- What does the training environment look like?

- How is the composition of the training group? Do they know each other? How many people are trained?

- Which aspects of the training work out well and which do not?

- How are the training sessions evaluated?

- Which factors make a CRM training successful? 
Answering these questions offers the opportunity to improve the future design and adaptation of CRM. Successful CRM trainings, in turn, can help minimize human error and increase safety standards in high-risk work domains.

Hence, the objective of this paper is threefold. First, this study seeks to outline the current state of CRM in aviation and other industries by offering detailed information about the training programmes. Second, it is essential to clarify what works well within the training and what does not. Thus, this study also focuses on lessons learned by trainers who conducted CRM training. Finally, some determined success factors for CRM will be presented.

\section{METHOD}

Semi-structured interviews were conducted to answer the questions discussed above. The 10 participants were experts working in different industries: civil aviation $(n=3)$, military aviation $(n=2)$, aircraft engineering $(n=2)$, fire service $(n=1)$, seafaring $(n=1)$ and medicine $(n=1)$. Each of them had at least three years of CRM experience.

As a first step, CRM experts were identified and contacted by e-mail. They were informed about the intended interviews and requested for their participation. After fixing dates with the experts and reviewing the interview questions in a pretest, telephone interviews were conducted.

All interviews were conducted by the same interviewer and lasted 25 minutes to 1 hour. The interviews were recorded for safeguarding all information. Next, recordings were transcribed with the help of a transcription software. During the transcription process, a rule system was used to ensure that all interviews were transcribed in the same way. Afterwards, a qualitative content analysis was applied to reduce the large amount of text to a manageable version that still included the essential aspects [19]. Based on the collected data from the interviews, categories were created.

In the next step, the categories had to be reviewed to verify their traceability. In addition to the coder himself, this was done by a second, independent coder in order to raise the intersubjectivity of the qualitative analysis. Further, the second coder assigned categories to the relevant text passages. Next, inter-rater reliability for the two coders was assessed by calculating Cohen's kappa. Cohen's kappa is a measure of reliability among two raters. It is the proportion of agreement corrected for chance [20]. A kappa value can vary from 0 to 1 , where 1 is an almost perfect agreement. In this study, a kappa value of 0,748 was achieved, which is defined as substantial [21]. This result proved the traceability of the category system and allowed an interpretation of the results.

\section{RESULTS}

Due to the fact that domains besides the aviation industry were only represented by single experts, the extent of validity of their statements for the respective industries is questionable. Thus, we will focus on cross-industry findings by presenting the results based on the experts' interviews. Nonetheless, industry-specific saliences will be mentioned, too.

\subsection{Current state of CRM}

\subsubsection{Trainer aspects}

The created categories regarding the trainer aspects show that 7 of 10 experts have specific CRM trainer education. It is noticeable that six of these experts work in the aviation industry. The seventh expert currently works in the seafaring industry, but also began to work in aviation. With regard to the guidelines in the aviation industry, it can be assumed that train- 
ers there require specific CRM trainer education. All experts trained either alone or at least in sets of two. Half of the experts carried out training by themselves, while others were supported by a second or third person. According to them, this is often an issue of resources.

\subsubsection{Analysis of needs}

In most cases, there was no systematic analysis of training needs on part of the trainers. Especially in the aviation industry, training sessions are based on the guidelines of aviation authorities. Further, it seems that current circumstances and the company's problems are indicators for the training needs. This category was found in five cases.

\subsubsection{Training contents and methods}

As mentioned previously, contents of CRM training in the aviation industry in Europe are determined. Therefore, experts in this area often only referred to these guidelines when they were asked which contents are used. Nonetheless, it is noticeable that the non-technical skills like cooperation, leadership, managerial skills, situation awareness and decision making are delivered through training across the different industries. Cooperation and situation awareness were skills most frequently used. Additionally, some industry-specific focuses were also present. It is interesting to note that topics like fatigue or passenger management especially matter in civil aviation. The topic 'stress' was also pointed out by the experts in civil aviation as well as in medicine and seafaring. This may be related to the specific industries. Contrary to aircraft engineering where error tends to become visible later (e.g. because of insufficient maintenance, a screw thread itself only during the flight), these are areas in which error often has a direct effect on the teams themselves and the relevant environment. This immediate threat further increases stress levels. The trainers working in aircraft engineering and military aviation sectors emphasised that they used the 'SHELL' model and error models like the 'Dirty Dozen concept'. This is probably because these concepts were originally conceptualised in and for the aviation industry.

Concerning the didactic methods, it became clear that all experts preferred varied methods during training. The most commonly used method is the lecture. Methods also used frequently include role play, pair and group work, discussions and examples in the form of case studies or narrations. Newer methods like e-learning were only mentioned by one expert (aircraft engineering). Complementary to the lecture as the most commonly used method, the most commonly used materials were PowerPoint presentations and flip charts. Moreover, videos and pictures were shown within the training sessions and sometimes worksheets were used.

\subsubsection{General conditions}

The created categories concerning the general conditions involve the training environment, the group of participants and duration of training. The categories for the training environment show that CRM training was conducted in the usual seminar rooms in all industries. In addition, there were categories that indicated industry-specific peculiarities. The fire service CRM expert explained that training took place at work, but sessions were interrupted occasionally by a fire-fighting operation. The seafaring CRM expert emphasised that some participants had to disrupt their holidays to attend training. This may be because these training sessions are not mandatory in these industries.

With regard to the group of participants, group size and composition can be distinguished. Group size varied cross-industrially from a minimum of 12 up to 20 or (maximum) 
24 participants. With a maximum of 12 , the civil aviation industry has the highest restriction on group size of participants. The participants either already knew each other or were introduced to each other during training. The sole case of not knowing each other was mentioned in the aviation industry. This may be on account of frequently changing teams in everyday work. Moreover, experts from military and civil aviation pointed out that they often worked with heterogeneous groups. This is caused by different hierarchy levels (e.g. cockpit and cabin crew) that usually trained together. Altogether, most experts alluded a group composition, which differs from training to training as well as with respective clients.

Categories about duration of training were derived from four interviews. Three trainers (civil and military aviation) tended to have one day for a CRM training, while the seafaring industry expert conducted training over three days.

\subsubsection{Evaluation}

Referring to the evaluation of training, almost all experts pointed out that it is not possible to evaluate a CRM training on all four levels of Kirkpatrick's evaluation model. This result aligns with a meta-analysis from Salas and his colleagues who barely found studies that evaluated CRM training on all four levels [14]. The majority of interviewed experts emphasised a focus on participants' reactions during evaluation. In the aviation industry, knowledge tests are also administered to participants. Further, some experts highlighted the idea of an informal evaluation, which can be an occasional encounter with the participants, for example. Thereby, participants often report what they liked during the training and what was useful in their everyday work.

\subsection{Lessons learned}

\subsubsection{Lessons from trainer aspects}

As mentioned previously, the number of trainers within a CRM training is often an issue of available resources. However, some experts highlighted the positive experience of conducting a training with two or more trainers. Additional categories indicate the need for certain trainer competencies such as knowledge in the relevant field of work.

\subsubsection{Lessons from analysis of needs}

The CRM expert from the medical industry emphasised the relevance of an analysis of competencies. Especially with regard to adaptation of CRM in other industries, it is important to know which competencies are necessary in the occupational area.

\subsubsection{Lessons from training contents and methods}

Considering the created categories regarding training contents and methods, it became clear that teaching theory in the specific field of work is crucial. Therefore, a very popular method across industries is the use of examples and case studies. Other popular methods are group exercises and role play. Moreover, it seems that a varied use of methods is important. Generally, expert interviews showed that participants prefer active methods, in terms of PowerPoint presentations, instead of lectures.

\subsubsection{Lessons from general conditions and evaluation}

Almost every expert alluded that the general conditions and resources restrict the training design. A notable aspect here is time. Some experts emphasised that the available time for 
training was too less. In addition, some categories indicate that evaluation of the training sessions often is neglected because of deficient resources. Two experts also reported a lack of interest by clients. They experienced that most clients do not react until an error occurs, which is harmful to the company or environment.

With regard to training environment, the statements of three experts (medicine, fire service, military aviation) suggest that it is better to conduct training outside the company. In medical and fire service sectors, this is because of on-call times, which often result in interrupted training. In military aviation, training outside the company is helpful to disregard the participants' ranks.

Moreover, the interviews also supplied evidence to lessons learned regarding the group of participants. A cross-industrial category elucidates that group size of 10-12 participants seems best. About half the interviewed experts found too less or too many participants difficult to manage. This is because trainers either could not take all participants into consideration or participants had to interact more than usual in smaller groups. With regard to group composition, it seems that an effective group composition often depends on the particular situation, for example, whether it is a reflection or addressing a specific problem. Another category comprised participants' acceptance. Many experts mentioned that it is hard to convince some participants, such as experienced employees, of the training programme. Further, it was learned that it is important to consider cultural aspects. One aircraft engineering expert emphasised the notable role of cultural influences, which needs to be respected during training.

\subsection{Success factors}

\subsubsection{Trainer aspects}

One cross-industrial success factor appears to be the credibility and expertise of the trainer. Some experts underlined that you can show credibility and expertise by living and showing the CRM spirit. Moreover, the trainer should have knowledge of the respective field, so that he or she can empathise with participants. Another element that makes CRM training successful is sensitisation of participants to the subject of CRM. This means that the trainer should make them aware of the importance of human factors by pointing out the everyday hazards that can cause human error.

\subsubsection{Training design}

The answers to the question for the success factors of CRM show similarities to the lessons learned of the trainers. Thus, we already indicated the importance of an application-oriented training combined with the usage of many examples related to everyday work. Some experts underlined again that active and varied training methods should be employed rather than simply delivering a theory-based lecture.

In addition, civil aviation experts pointed out that communication as a connecting element during a CRM training may be a further factor for success.

\subsubsection{General conditions}

The success factors regarding the general conditions arose from interviews with civil and military aviation experts as well as with the seafaring expert. Once again, these experts highlighted the importance of having sufficient time for training. It became clear that an organisational culture, which supports CRM and ensures its sustainability, is required. 
Table 1: Result overview.

\begin{tabular}{|c|c|}
\hline & Results \\
\hline Current state & $\begin{array}{l}\text { - Trainers who already conducted a CRM training in aviation industry } \\
\text { have specific CRM trainer education. } \\
\text { - Training needs are usually based on current circumstances and prob- } \\
\text { lems. } \\
\text { - Non-technical skills are core components of a training. Additionally, } \\
\text { there seems to exist industry-specific topics, e.g. fatigue in aviation } \\
\text { industry. } \\
\text { - Several methods and materials are used. } \\
\text { - CRM training often takes place in seminar rooms. } \\
\text { - Group size varies from } 12 \text { to maximum } 24 \text { participants. Group compo- } \\
\text { sition also varies. }\end{array}$ \\
\hline Lessons learned & $\begin{array}{l}\text { - Performing a training with two or more trainers is helpful. } \\
\text { - Trainers should use examples related to the field of work to produce } \\
\text { application orientation. } \\
\text { - The use of different methods is important. } \\
\text { - General conditions and resources limit training design and evaluation. } \\
\text { - It can be useful to organise the training outside the company. } \\
\text { - Ideal group size: } 10-12 \text { participants. Too less or too many participants } \\
\text { are difficult to handle. }\end{array}$ \\
\hline Success factors & $\begin{array}{l}\text { - A credible and competent trainer who is able to sensitise the partici- } \\
\text { pants for the topic is needed. } \\
\text { - Training with strong references to the related work field, activation and } \\
\text { varied exercises are necessary. } \\
\text { - Good general conditions, e.g. having enough time for the trainings, are } \\
\text { effective. }\end{array}$ \\
\hline
\end{tabular}

\subsection{Overview of results}

Table 1 summarises the discussed results whereby the focus is on cross-industrial results.

\section{DISCUSSION AND CONCLUSION}

Qualitative interviews are a valuable tool for finding out extensive information. The current study obtained numerous results regarding CRM. This section discusses the results by considering the study's strengths and limitations. Last, implications for CRM training and recommendations for future research will be presented.

\subsection{Strengths and limitations}

Like all research, this study has both strengths and limitations. A need for improvement towards CRM training can be deduced from the expert interviews. All participants showed interest in the investigation and responded extensively to every question. The results fulfil the defined objectives and offer detailed information about CRM training. Moreover, lessons 
learned and success factors were gained from the interviews, which may help to improve future training. Another positive aspect is the high kappa value of 0,748 , which ensures interrater reliability. It demonstrates the result's independence of the researcher and valorises the study's significance.

Beside these strengths, there are also some noteworthy limitations of the study. First, it was a qualitative study with a small sample. Thus, the study may only reflect partial opinions. In addition, most experts were from the aviation industry and only single experts from other industries participated. Therefore, CRM-related information in non-aviation industries where CRM is not obligatory would be interesting and helpful for future adaptation. As already mentioned, previous research also did not sufficiently take CRM in other industries into account. It seems to be generally difficult to find studies or experts that can provide detailed information about the application of CRM in non-aviation industries. Another critical issue is the mix of practitioners and scientists in the sample. Most experts were practitioners, but two experts who participated also gained experience from an empirical study. They often emphasised that they had more opportunities compared to those common in practice. Further, there is a limitation concerning the interview questions. The results show that not all relevant aspects about CRM were covered adequately by the interviews. One expert highlighted the importance of cultural aspects, but this topic was not considered in the interview manual. hence, no more information regarding cultural aspects in CRM training could be deduced from the interviews. Also, increasing internationalisation would have been an interesting aspect for the interview manual.

\subsection{Implications for CRM training}

Altogether, this study demonstrates the complexity of CRM and its application. A large amount of results was deduced from the interviews, and the research questions were clarified. Nevertheless, there is still a need for more detailed information regarding CRM, especially in other industries. The results of this study show that there are both positive and negative aspects about CRM training. The lessons learned, as mentioned by the experts, may help to improve the future training design of CRM. CRM practitioners of various industries can benefit from the study findings and learn from each other's experience.

Human error is omnipresent. Even in the future, there will be many major accidents caused by human error. A good human factors training may help to reduce human error and increase safety in high-risk industries. Therefore, future research should spend time in optimising CRM training. It would be particularly interesting to find out more about the aspects that were treated with less significance in this study, such as the cultural influences within a training.

\section{REFERENCES}

[1] Reason, J., Human Error, Cambridge University Press, 1990. http://dx.doi.org/10.1017/CBO9781139062367

[2] Helmreich, R.L., Merritt, A.C. \& Wilhelm, J.A., The evolution of crew resource management training in commercial aviation. The International Journal of Aviation Psychology, 9(1), pp. 19-32, 1999. http://dx.doi.org/10.1207/s15327108ijap0901_2

[3] Safety Regulation Group, Crew Resource Management (CRM) training. Guidance for flight crew, CRM instructors (CRMIS) and CRM instructor examiners (CRMIES), Civil Aviation Authority, Norwich, UK: TSO, p.1, 2006. 
[4] Flin, R., Martin, L., Goeters, K.M., Hörmann, H.J., Amalberti, R., Valot, C. \& Nijhuis, R., Development of the NOTECHS (non-technical skills) system for assessing pilots' CRM skills. Human Factors and Aerospace Safety, 3(2), pp. 95-117, 2003.

[5] European Aviation Safety Agency, Acceptable Means of Compliance (AMC) and Guidance Material (GM) to Part-ORO, available at http://easa.europa.eu/system/files/dfu/ Annex\%20to\%20ED\%20Decision\%202014017-R\%20-\%20Part-ORO_0.pdf.

[6] Federal Aviation Administration, Crew Resource Management Training (Advisory Circular No: 120-51E), Washington, DC: U.S. Department of Transportation, 2004.

[7] Helmreich, R.L., On error management: lessons from aviation. British Medical Journal, 320, pp. 781-785, 2000.

http://dx.doi.org/10.1136/bmj.320.7237.781

[8] Flin, R., O’Connor, P. \& Mearns, K., Crew resource management: improving team work in high reliability industries. Team Performance Management: An International Journal, 8, pp. 68-78, 2002.

http://dx.doi.org/10.1108/13527590210433366

[9] Hayward, B.J. \& Lowe, A.R., The migration of crew resource management training. Crew Resource Management, eds. B.G. Kanki, R.L. Helmreich \& J. Anca, Academic Press: San Diego, pp. 317-342, 2010.

[10] Lubnau II, T.E. \& Okray, R., Crew Resource Management for the Fire Service, available at http://www.fireengineering.com/articles/print/volume154/issue8/features/ crew-resource-management-for-the-fire-service.html, 2001.

[11] Marquardt, N., Robelski, S. \& Hoeger, R., Crew resource management training within the automotive industry: does it work? Human Factors, 52, pp. 308-315, 2010. http://dx.doi.org/10.1177/0018720810366258

[12] O'Connor, P., Assessing the effectiveness of bridge resource management training. The International Journal of Aviation Psychology, 21(4), pp. 357-374, 2011. http://dx.doi.org/10.1080/10508414.2011.606755

[13] O'Connor, P., Flin, R. \& Fletcher, G., Techniques used to evaluate crew resource management training: a literature review. Human Factors and Aerospace Safety, 2(3), pp. 217-233, 2002.

[14] Strohschneider, S., Human-factors-training. Human Factors, ed. P. BadkeSchaub, G. Hofinger \& K. Lauche, Springer Verlag: Heidelberg, pp. 313-332, 2012.

[15] Salas, E., Wilson, K.A., Burke, C.S. \& Wightman, D.C., Does crew resource management training work? an update, an extension, and some critical needs. Human Factors, 48, pp. 392-412, 2006.

http://dx.doi.org/10.1518/001872006777724444

[16] Salas, E., Prince, C., Bowers, C.A., Stout, R.J., Oser, R.L. \& Cannon-Bowers, J.A., A Methodology for enhancing crew resource management training. Human Factors, 41, pp. 161-172, 1999. http://dx.doi.org/10.1518/001872099779577255

[17] Salas, E., Burke, C.S., Bowers, C.A. \& Wilson, K.A., Team training in the skies. does crew resource management training work? Human Factors, 43, pp. 641-674, 2001. http://dx.doi.org/10.1518/001872001775870386

[18] Salas, E., Diaz Granados, D., Klein, C., Burke, C.S., Stagl, K.C., Goodwin, G.F. \& Halpin, S.M., Does team training improve team performance? a meta-analysis. Human Factors, 50, pp. 903-933, 2008.

http://dx.doi.org/10.1518/001872008X375009 
[19] Mayring, P., Qualitative Inhaltsanalyse. Grundlage und Techniken, Beltz Verlag: Weinheim, Basel, 2010.

http://dx.doi.org/10.1007/978-3-531-92052-8_42

[20] Cohen, J., A coefficient of agreement for nominal scales. Educational and Psychological Measurement, 20, pp. 37-46, 1960.

http://dx.doi.org/10.1177/001316446002000104

[21] Landis, J.R. \& Koch, G.G., The measurement of observer agreement for categorical data. Biometrics, 33, pp. 159-174, 1977.

http://dx.doi.org/10.2307/2529310 